\title{
FORMAÇÃO CONTINUADA DE PROFESSORES INICIANTES NA PROFissão: CONTRIBUiÇões do PROJeto “SABeres EM DiÁlOGo"
}

\author{
CONTINUING EDUCATION OF BEGINNING TEACHERS: “SABERES EM DIÁLOGO” PROJECT \\ CONTRIBUTIONS
}

\author{
FORMACIÓN CONTÍNUA DE DOCENTES PRINCIPIANTES EN LA PROFESIÓN: \\ CONTRIBUCIONES DEL PROYECTO “SABERES EN DIÁLOGO”
}

\section{Gilberto Ferreira da Silva \\ iD 9 \\ Doutor em Educação (UFRGS) \\ Docente no Programa de Pós \\ Graduação em Educação da \\ UNILASALLE \\ gilberto.ferreira65@gmail.com}

\section{Juliana Aquino Machado \\ (iD) 9}

Mestra em Educação

Professora na Rede Municipal de

Ensino de Canoas

Discente no Programa de Pós

Graduação em Educação da

UNILASALLE

juliana.machado@canoasedu.rs.gov.br

\section{Ana Paula da Silva

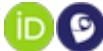

Mestra em Literatura Brasileira

Professora na Rede Municipal de

Ensino de Canoas

Discente no Programa de Pós

Graduação em Educação da

UNILASALLE

ana.psilva@canoasedu.rs.gov.br

\section{Juliana Cristina da Silva (iD) 9}

Mestra em Educação

Professora na Rede Municipal de

Ensino de Canoas

Discente no Programa de Pós

Graduação em Educação da

UNILASALLE

juliana.silva@canoasedu.rs.gov.br

\begin{abstract}
Resumo
O objetivo é compreender como os professores, com até 5 anos de inserção profissional, percebem os efeitos da formação continuada experimentada e que contribuições são possíveis desprender da experiência para a sua qualificação profissional. A produção dos dados amparou-se em um questionário, aplicado ao conjunto de educadores participantes do projeto Saberes em Diálogo. Recorreu-se às orientações oferecidas pela hermenêutica-dialética para o tratamento dos dados. Para a análise e interpretação, buscou-se as contribuições da descolonialidade. $\mathrm{O}$ estudo evidenciou o quanto a inserção de novos profissionais na área da docência se apresenta como um campo ainda a ser explorado a partir da perspectiva da produção acadêmica e na formulação de políticas públicas formativas. $\mathrm{Na}$ percepção dos professores identificou-se que o Projeto Saberes em Diálogo contribui para a inserção docente na profissão, estimula o diálogo entre pares e possibilita um maior entrosamento na relação com a Secretaria Municipal da Educação.
\end{abstract}

Palavras-chave: Formação Docente. Projeto Saberes em Diálogo. Inserção profissional Docente.

Recebido em: 22 de fevereiro de 2021.

Aprovado em: 21 de abril de 2021.

Como citar esse artigo (ABNT):

SILVA, Gilberto Ferreira da et al. Formação continuada de professores iniciantes na profissão: contribuições do Projeto "Saberes em Diálogo". Revista Prática Docente, v. 6, n. 1, $\mathrm{e} 025,2021$.

http://doi.org/10.23926/RPD.2021.v6.n1.e025.id1056 


\section{Abstract}

The objective is to understand how teachers, with up to 5 years of professional insertion, perceive the effects of the continued education experienced and what contributions it is possible to derive from the experience for their professional qualification. The production of the data was supported by a questionnaire, applied to the group of educators participating in the Saberes em Diálogo project. The guidelines offered by hermeneuticsdialectics were used for the treatment of data. For the analysis and interpretation, contributions from the decoloniality. The study showed how much the insertion of new professionals in the teaching field presents itself as a field yet to be explored from the perspective of academic production and in the formulation of education public policies. In the perception of teachers, it was identified that the Saberes em Diálogo Project it contributes to the teaching insertion in the profession, stimulates the dialogue between peers and enables a better relationship with the Municipal Secretariat of Education.

Keywords: Teacher Training. Saberes em Diálogo Project. Teaching professional insertion.

\section{Resumen}

El objetivo es comprender cómo los docentes, con hasta 5 años de inserción professional, perciben los efectos de la formación continua experimentada y qué contribuciones es posible obtener de la experiencia para su calificación profesional. La producción de datos apoyouse em un cuestionario, aplicado al grupo de educadores que participan del proyecto Saberes em Diálogo. Tomamos las contribuciones de la hermenéutica-dialéctica para procesar los datos. Para el análisis e interpretación, se buscaron los aportes de la descolonialidad. El estudio mostró hasta qué punto la inserción de nuevos profesionales en el campo de la enseñanza se presenta como un campo aún por explorar desde la perspectiva de la producción académica y en la formulación de políticas públicas de formación. En la percepción de los docentes, se identificó que el Proyecto Saberes em Diálogo contribuye a la inserción docente en la profesión, estimula el diálogo entre pares y posibilita una mejor relación con el Secretaría Municipal de Educación.

Palabras clave: Formación de profesores. Proyecto Saberes em Diálogo. Inserción Profesional Docente. 


\section{INTRODUÇÃO}

As concepções atuais de formação docente vêm sendo reconfiguradas, numa perspectiva que a considera como algo inerente à profissão, assumindo um caráter de formação permanente, que se desenvolve no decorrer da vida (VAILLANT, 2016; VAILLANT e GARCIA, 2015; ANDRÉ, 2018, GATTI, 2017; GATTI et.al, 2019). A compreensão que durante muito tempo perdurou no campo da formação de professores, apoiada na ideia da formação continuada adquirindo um caráter compensatório, de forma a suprir as lacunas da formação inicial, vem se distanciando das práticas e sendo objeto de crítica.

Vaillant (2016) tem trabalhado acerca desta questão, pontuando sobre o esgotamento do modelo que considera suficiente para o exercício do trabalho docente a bagagem de conhecimentos adquiridos na formação inicial, acrescidos da experiência. Para a autora, o desenvolvimento profissional docente implica necessariamente a interação e a colaboração entre pares, sendo este um processo permanente, contínuo e inerente ao fazer docente.

Colocamo-nos num movimento de pensar em duas perspectivas. A primeira delas diz respeito a não desconsiderar a relevância da formação inicial na constituição docente, ainda que seja necessário investir num maior estreitamento entre os conhecimentos trabalhados na Universidade e os desafios dos contextos de trabalho. Gatti (2017, p. 725) sinaliza, já há algum tempo, que "a formação de professores nas licenciaturas, hoje, mostra-se justamente em choque direto com as demandas do trabalho escolar a ser realizado na educação básica". A segunda perspectiva diz respeito a reposicionar a discussão sobre a formação continuada em relação à formação inicial. Ainda que a formação inicial estivesse articulada com a realidade das escolas e mesmo que esta etapa criasse condições plenas para que os professores iniciantes desempenhassem suas atividades docentes, a fluidez e dinamicidade dos contextos demanda uma necessidade permanente de adaptação, de atualização e de uma formação que coloque os sujeitos e seus desafios cotidianos na centralidade dos processos formativos.

O cotidiano foi o principal elemento mobilizador do Projeto Saberes em Diálogo (SILVA e MACHADO, 2018) a partir do ano de 2018. Embora "nascido" no ano anterior, no intuito de conhecer e dar visibilidade às pesquisas em nível de Pós-Graduação dos professores pesquisadores da rede (MACHADO, LEDUR e SILVA, 2018), foi em 2018 que o Saberes em Diálogo ${ }^{1}$ passou a se fundamentar na prerrogativa da qualificação da Educação Básica partindo

\footnotetext{
${ }^{1}$ Para mais detalhes do Projeto Saberes em Diálogo, sugerimos a leitura do artigo de Silva e Machado (2018). Os autores retratam o início e os desdobramentos que o projeto, realizado em parceria com o
} 
de um movimento que coloca em diálogo as práticas, os saberes e os desafios do espaço da escola.

A partir de estratégias, pensadas e propostas no intuito de oferecer subsídios aos professores, mobiliza-se a rede municipal de ensino, apostando que a investigação acerca dos desafios cotidianos, numa dinâmica pautada pelo protagonismo e pela coletividade, pode conduzir à construção de alternativas que, de fato, impactem positivamente no trabalho docente. Sob esta ótica, o estudo aqui apresentado debruça-se sobre o coletivo de professores envolvidos no Saberes em Diálogo em 2019; entretanto, deste coletivo, analisa-se a realidade daqueles que se encontram no início de sua trajetória docente, tendo até cinco anos de experiência com o exercício do magistério (na Rede Municipal de Ensino de Canoas (RMEC) ou fora dela).

Segundo Ávalos (2009), a inserção profissional do professor iniciante constitui uma etapa chave na configuração de sua identidade como docente. A hipótese com a qual trabalhamos é de que um projeto de formação continuada de professores, no caso o Saberes em Diálogo, apresenta potencialidades para apoiar a inserção profissional dos docentes iniciantes, contribuindo na superação dos desafios próprios dos contextos educativos nos quais estão inseridos. Assim, procura-se compreender como os professores com até cinco anos de inserção profissional percebem os efeitos e as contribuições para sua qualificação considerando a formação continuada experimentada no projeto. Entendemos que conhecer as concepções que estes professores têm sobre formação continuada seja ponto de partida para esta análise.

Para a organização deste trabalho, lançamos mão de uma estrutura que parte do que a literatura no campo da formação continuada de professores iniciantes tem configurado como principais preocupações. O que se intenciona é produzir uma síntese dos avanços na pesquisa, aproveitando esforços realizados em artigos de revisão de literatura, tão comuns na cultura de produção de trabalhos acadêmicos. A segunda parte foca na descrição dos elementos metodológicos que amparam a produção dos dados e de onde eles emergem. Aqui reside a preocupação em oferecer os aspectos necessários para a compreensão do contexto e a forma como foram gerados os dados aqui tratados e analisados. A terceira parte explora os resultados obtidos pela pesquisa, analisando-os à luz de um referencial teórico que vai sendo apresentado à medida que os dados vão exigindo modos outros de compreensão.

PPGEDU/Universidade La Salle, vem tendo no trabalho formativo da RMEC. De igual maneira,encontra-se uma síntese no trabalho de Gatti et all. (2019). 
Procura-se manter o diálogo aberto com a produção clássica na área, agregando e procurando construir a interpretação e a análise, de tal forma que permitam ampliar horizontes outros, formas de compreender o que se passa com educadores em inserção na profissão, assim como o lugar ocupado por ações que visam à qualificação da ação docente. Finalmente, em formato de síntese, apresentam-se os resultados do que a análise permitiu extrair.

\section{ProfESSORES INICIANTES NA CARREIRA DOCENTE}

Como alerta Garcia (2010), os processos que interferem e colaboram com a construção das identidades docentes são contínuos e comportam experiências ao longo da vida. Em grande parte, essas experiências acabam não se constituindo em objeto de reflexão, mas vão sendo paulatinamente incorporadas, mediadas muito mais por aspectos emocionais do que cognitivos. Resulta que modelos vão sendo associados e eleitos neste processo, identificando um modo de ser e atuar na profissão. Assim, as interações sociais constituem-se como fator inerente ao próprio ato de ensinar e não é de se estranhar que os educadores, em geral, estejam firmemente comprometidos com seu trabalho, pois no dizer de Garcia (2010, p.13) "Esse vínculo entre os aspectos emocionais e cognitivos da identidade profissional docente deve ser levado em conta na hora de analisar a profissionalização docente".

Essa característica traduz, em grande medida, um dos princípios que orienta o trabalho formativo no Projeto Saberes em Diálogo. O princípio "pertencimento" (SILVA e MACHADO, 2020) emerge do fato de que a adesão ao projeto se dá de forma voluntária e, portanto, tem permitido um grau significativo de pertencimento à proposta por parte dos educadores, desde sua gênese (SILVA e MACHADO, 2018). Além da adesão voluntária, a possibilidade do encontro entre pares, na superação da solidão pedagógica (ISAIA; BOLZAN, 2008) também mobiliza e coloca o professor como parte de um projeto, de um trabalho, de um coletivo, tanto pela identificação quanto pela possibilidade de exercício da alteridade, próprio de qualquer dinâmica que pressuponha um grupo (GATTI, 2020).

Em reuniões da Comissão Coordenadora ${ }^{2}$, do Projeto Saberes em Diálogo, ouviu-se em algumas oportunidades expressões tais como: "Eu pesquisei a escola no meu trabalho de doutorado, mas agora na condição de professor da Educação Básica é que de fato estou

\footnotetext{
2 O Projeto Saberes em Diálogo é conduzido de forma colegiada por uma Comissão Coordenadora, composta por assessores pedagógicos da SME, professores que desempenham suas atividades docentes na escola, tanto na sala de aula quanto na equipe diretiva e professores da Universidade La Salle, constituindo um coletivo de 26 docentes em 2019.
} 
aprendendo sobre o que é a escola. Eu me pergunto: que pesquisa foi aquela que eu realizei?" (Doutora em Educação, 3 anos de atuação na RMEC). Ou ainda: "Poder participar das atividades do Saberes em Diálogo abriu possibilidades de ver que o que eu estava fazendo em sala de aula encontra sentido no trabalho dos colegas, isso me dá segurança" (Mestra em Educação, 2 anos de atuação na RMEC).

Os professores iniciantes se deparam com um processo tenso e, não raras vezes, permeado pela insegurança. Garcia (2010, p. 29) sintetiza da seguinte maneira as exigências enfrentadas pelo professor iniciante: "adquirir conhecimentos sobre os alunos, o currículo e o contexto escolar; delinear adequadamente o currículo e o ensino; começar a desenvolver um repertório docente que lhes permita sobreviver como professor [...]”. Para além destas, o trabalho de gestão em sala de aula e a continuidade do seu desenvolvimento profissional se somam às exigências do que o educador deve responder no cotidiano da ação docente.

André (2018), em um estudo sobre professores iniciantes no contexto brasileiro, recorre a um conjunto de trabalhos que se propõem a produzir uma revisão do tipo estado da arte ou revisão de literatura, abarcando períodos da produção. Dentre os estudos, a análise dos trabalhos apresentados nas reuniões da Associação Nacional de Pesquisa e Pós-Graduação em Educação (ANPEd) e nos Encontros Nacionais de Didática e Prática de Ensino (ENDIPEs) de 1995 a 2004 revelam que somente 24 pesquisas tratavam da temática do professor iniciante dentro de um universo total de 6978 textos localizados. Ou seja, o que se constata, para além da escassez de estudos, é também uma ausência de sensibilização de pesquisadores ao tema.

$\mathrm{Na}$ continuidade, a autora, procurando apresentar uma síntese dos avanços da pesquisa nesta área, atualiza a discussão recorrendo a outros estudos que contemplam períodos de revisão mais recentes, como é o caso do trabalho realizado por Gonçalves (2016) e citado por André (2018). Neste estudo, o autor continua o mapeamento de pesquisas sobre professores iniciantes na carreira docente, explorando os textos apresentados em períodos recentes, tanto na ANPED (2012-2015) quanto no ENDIPE (2012-2014), assim como trabalhos apresentados no Congresso Internacional sobre Professores Principiantes e Inserção Profissional (CONGEPRINCI, 2014). Este levantamento acabou por contemplar um período de mapeamento que inicia em 1995 e vem até 2015, perfazendo cerca de 20 anos de produção. André (2018) reforça a constatação dos estudos iniciais sobre a necessidade de maior atenção ao tema, e acrescenta: 
(...) os resultados das pesquisas são recorrentes: voltam-se aos dilemas e tensões vividos no início da carreira, ao choque de realidade, aos processos de socialização e desenvolvimento profissional e reafirmam a ausência, no Brasil, de políticas e programas voltados aos professores que ingressam na docência (ANDRÉ, 2018, p.6).

A necessidade de tais estudos reside especialmente no hiato observado entre a formação inicial e a inserção no trabalho docente (GABARDO; HOBOLD, 2013). Não raros são os relatos acerca da chegada dos professores iniciantes na escola que, ao se depararem com as situações próprias deste contexto cotidiano, apresentam dificuldades em lidar, ocasionando em alguns casos, inclusive, o abandono da profissão. Ávalos (2009) aponta que o professor iniciante enfrenta demandas ou conflitos no local de trabalho, recebendo e fazendo perguntas que nem sempre são respondidas, pois "acolhe, rejeita, interpreta e reinterpreta essas experiências como uma espécie de reconfiguração da identidade profissional que ele talvez pensasse ter adquirido em sua formação inicial” (ÁVALOS, 2009, p. 44).

As experiências primeiras de ensino do professor iniciante, "mediadas pelos contextos de trabalho, suas demandas, suas satisfações ou seus conflitos, produzem revisões na maneira como o novo professor se via ao deixar a instituição formadora" (AVALOS, 2009, p. 54), o que permite afirmar sobre a importância de programas de indução docente como uma política formativa comprometida e articulada com as necessidades da educação. É necessário entender que: "A identidade profissional do professor possui, portanto, elementos referentes à decisão pessoal ou motivação para o ensino, que por sua vez pode ter várias origens [...]" (ÁVALOS, 2009, p. 51-52).

Os desafios enfrentados pelo professor iniciante, entretanto, não diferem significativamente dos desafios enfrentados pelos professores mais experientes. Referem-se muitas vezes a problemas de "gestão da disciplina em aula, da motivação dos estudantes, da organização do trabalho na turma, dos materiais insuficientes, dos problemas pessoais dos estudantes e das relações com os pais" (GARCIA e VAILANT, 2017, p. 1226).

Em recente revisão de literatura, Ávalos (2016) aponta que os relatórios publicados ou revisões de pesquisas sobre professores iniciantes, incluindo análises ou ensaios reflexivos com base em pesquisas acerca do tema "professor iniciante", entre os anos de 2001 e 2015, referemse principalmente a: a) descrição de programas de indução, processos e efeitos; b) processos de ensino e aprendizagem; c) aprendizagem profissional e fatores que afetam a evasão/retenção docente; d) crenças, atitudes, tensões, desafios e preocupações dos professores iniciantes; e) estudos sobre mentoria docente. Apesar da existência de algumas iniciativas de inserção docente, a experiência de novos professores continua a ser descrita como problemática e seu 
apoio é deixado em práticas informais em suas escolas, bem como em seus próprios esforços em procurar ajuda.

A existência de programas específicos a esta finalidade constitui uma faceta que traz relevância, contudo, sendo os desafios compartilhados entre os docentes iniciantes e os experientes (desafios próprios a cada contexto de trabalho), nos questionamos sobre o papel das escolas e das redes de ensino nessa entrada dos professores iniciantes na docência e que estratégias podem ser colocadas em prática, de forma a constituir um ambiente institucional estimulante, que atenda às necessidades deles. Para Ávalos (2016), é preciso pensar sobre até que ponto as culturas escolares oferecem oportunidade para novos professores encontrarem ambientes estimulantes de acordo com suas capacidades em desenvolvimento, além das capacidades relacionais dos professores incorporadas em suas aprendizagens espontâneas em conjunto ou em diferentes formas de trabalho colaborativo, promovidos tanto por instituições de formação de professores quanto pelas escolas.

\section{Metodologia do ESTUdo}

Arias (2010) provoca-nos a pensar sobre a potencialidade de propostas metodológicas que se apoiem em sabedorias insurgentes e que rompam com o sentido positivista, fragmentador, instrumental, homogeneizante e colonizador com o qual a ciência social historicamente se constituiu. Tal postura se pauta numa perspectiva metodológica que coloca a centralidade o compromisso com a vida, portanto, de caráter sentipensante ${ }^{3}$ : "Não será acaso a metodologia, senão isso, um caminho para poder chegar?; porém é um caminho que [...] deve ser construído por nós mesmos, mas em um contínuo diálogo e escuta de e com os outros(ARIAS, 2010, p. 492).

Essa postura, de caráter decolonial, nos (re)coloca necessariamente num espaço outro, que requer que as compreensões se pautem pela noção de que o conhecimento tem valor, cor, gênero e local de origem e que, portanto, o lugar do qual se pensa importa e a temporalidade e localidade estão associados, na perspectiva de criação de conhecimentos que atravessam fronteiras (WALSH, 2004). Para Walsh (2007), as epistemologias decoloniais apostam na produção de novos conhecimentos e modelos de análise, conceitualização e pensamento com uso estratégico e político, apoiados em três aspectos: atender os conhecimentos que eram

\footnotetext{
${ }^{3} \mathrm{O}$ termo sentipensante foi proposto por Orlando Fals Borda (2015) e se refere à possibilidade de atuar com o coração e empregar o racional cerebral ao mesmo tempo. Ainda, o termo sentipensante é utilizado com recorrência nas obras de Eduardo Galeano e de Catherine Walsh.
} 
considerados "não conhecimentos"; considerar os pensamentos e conhecimentos não em forma de universais, mas de forma plural, desde as diferenças coloniais; e pensar novos lugares para eles dentro e fora da universidade.

Este estudo, de abordagem qualitativa, tem como pano de fundo o Projeto Saberes em Diálogo (SILVA e MACHADO, 2018, 2020), que vem se constituindo no âmbito da RMEC como uma aposta em termos de formação continuada de professores feita desde onde se está, com as pessoas com quem se está (WALSH, 2009). O Saberes em Diálogo deu os primeiros passos em 2017, numa ação que objetivava conhecer e dar visibilidade às pesquisas em nível de pós-graduação dos professores da RMEC (MACHADO, LEDUR e SILVA, 2018). A partir de 2018, o foco das ações do projeto fundamenta-se na prerrogativa de que, para qualificar a Educação Básica, há de se partir de um movimento que coloca o chão da escola na centralidade. Ou seja, os desafios cotidianos passam a ser objeto de estudo dos professores, como intelectuais de sua prática, como pesquisadores e como protagonistas na busca de alternativas viáveis para qualificar seu fazer.

Dadas as transformações de foco com o qual o Saberes em Diálogo foi se constituindo, passou a ser uma das premissas da continuidade do trabalho conhecer o perfil dos professores participantes. Se, em 2017, a própria proposta direcionava o foco para os professores com formação em nível de pós-graduação, no sentido de conhecer as pesquisas desenvolvidas nesta etapa da formação, o redirecionamento conduz a um novo cenário: a proposta de construir projetos de pesquisa com foco no cotidiano da escola e nas demandas vividas neste espaço, amplia, assim, o público-alvo. Interessava-nos saber se os professores participantes do Saberes em Diálogo continuavam sendo os professores com maior formação acadêmica na RMEC ou se, conforme suspeitavam nossas impressões, os participantes agora tinham formação acadêmica diversa, não podendo ser mais este critério utilizado como descritor deste públicoalvo.

Nesse contexto, propôs-se, no ano de 2019 um questionário chamado "Perfil dos Professores Participantes do Projeto Saberes em Diálogo 2019”, através de um formulário do GoogleForms ${ }^{4}$. O questionário, composto por questões fechadas e abertas, foi encaminhado por e-mail para todos os professores que tinham inscrito pesquisas no ano de 2019. De um total de 287 participantes, tivemos o retorno de 83 professores.

\footnotetext{
${ }^{4}$ Ferramenta do Google que possibilita a criação de questionários para pesquisas, coleta de dados e enquetes.
} 
A análise preliminar dos dados, no âmbito das estratégias do projeto, levou a uma constatação. Do total de respondentes, verificou-se que 51 professores tinham até cinco anos de exercício profissional na Rede Municipal de Ensino, o que constitui $61 \%$ do total de participantes. Para fins deste estudo, selecionamos as respostas a partir do critério "tempo de exercício profissional na RMEC", ficando o corpus de análise constituído, portanto, pelas respostas de 51 professores, assim distribuídos por tempo de docência: 4\% com cinco anos, $31 \%$ com quatro anos, $25 \%$ com três anos, $16 \%$ com dois anos e $24 \%$ com um ano.

A análise das respostas mostrou também que o projeto Saberes em Diálogo estava, de fato, composto por professores com uma maior diversidade quanto à formação acadêmica, contemplando desde professores com a graduação em andamento até professores com doutorado completo, sendo: $57 \%$ dos docentes apontaram possuir curso de pós-graduação, nível especialização completo ou em andamento; $27 \%$ possuem curso de pós-graduação, nível mestrado ou doutorado completo ou em andamento e 16\% afirmaram ter somente graduação completa ou em andamento.

Do questionário proposto, foram apresentados dois conjuntos de perguntas. Um primeiro de respostas fechadas com o intuito de coletar informações pontuais e objetivas e um segundo, de respostas abertas, voltadas à conhecer em maior profundidade a percepção de cada um dos educadores.

Olhar para os dados produzidos constitui um momento que contempla tanto a análise quanto a interpretação, buscando promover o enriquecimento da leitura e possibilitar a integração das descobertas que vão para além das aparências (MINAYO, 1996; 2001). Sendo assim, a compreensão dos dados se dá durante todo o processo de pesquisa, ainda que haja "um dado instante de ênfase na construção e sistematização analítica e interpretativa", até porque a pesquisa não é só um processo ou estratégia acadêmica, mas um produto de final aberto (MACEDO, 2009, p. 97).

A perspectiva metodológica adotada neste estudo considera, além dos dados produzidos, "o contexto sócio-político-econômico e cultural onde o discurso circula" (MINAYO, 1996, p. 230), uma vez que o pano de fundo no qual se insere é elemento implicacional (MACEDO, 2009,2015 ) dos autores ${ }^{5}$. De igual forma, os dados produzidos constituem um "relato" de uma

\footnotetext{
${ }^{5}$ Salienta-se que os quatro autores da pesquisa em questão compõem a Comissão Coordenadora do Projeto Saberes em Diálogo', sendo três professoras da RMEC. Entendemos que o envolvimento subjetivo com a pesquisa a potencialize, uma vez que, segundo Macedo (2015), o envolvimento emocional com a pesquisa a ressignifica e qualifica os estudos de natureza qualitativa.
} 
vivência concreta e subjetiva, inserida no tempo e no espaço, pois, como aponta Macedo (2015, p. 26-27), "o corpo é o lugar onde se inscreve cada história singular, onde pensamentos e sentimentos se manifestam em palavras, em imagens. Aqui emergem os sentidos do vivido".

A interpretação dos dados foi conduzida por meio dos aportes da hermenêutica-dialética que, segundo Minayo (1996; 2001), constituem o método que melhor tem condições de possibilitar uma interpretação mais aproximada da realidade, uma vez que "a fala dos atores sociais é situada em seu contexto para melhor ser compreendida" (MINAYO, 2001, p. 77). Para operacionalizar a análise hermenêutica-dialética, a autora propõe a trajetória metodológica que está apresentada na Figura 1.

Figura 1 - Desenho da Interpretação hermenêutico-dialética dos dados

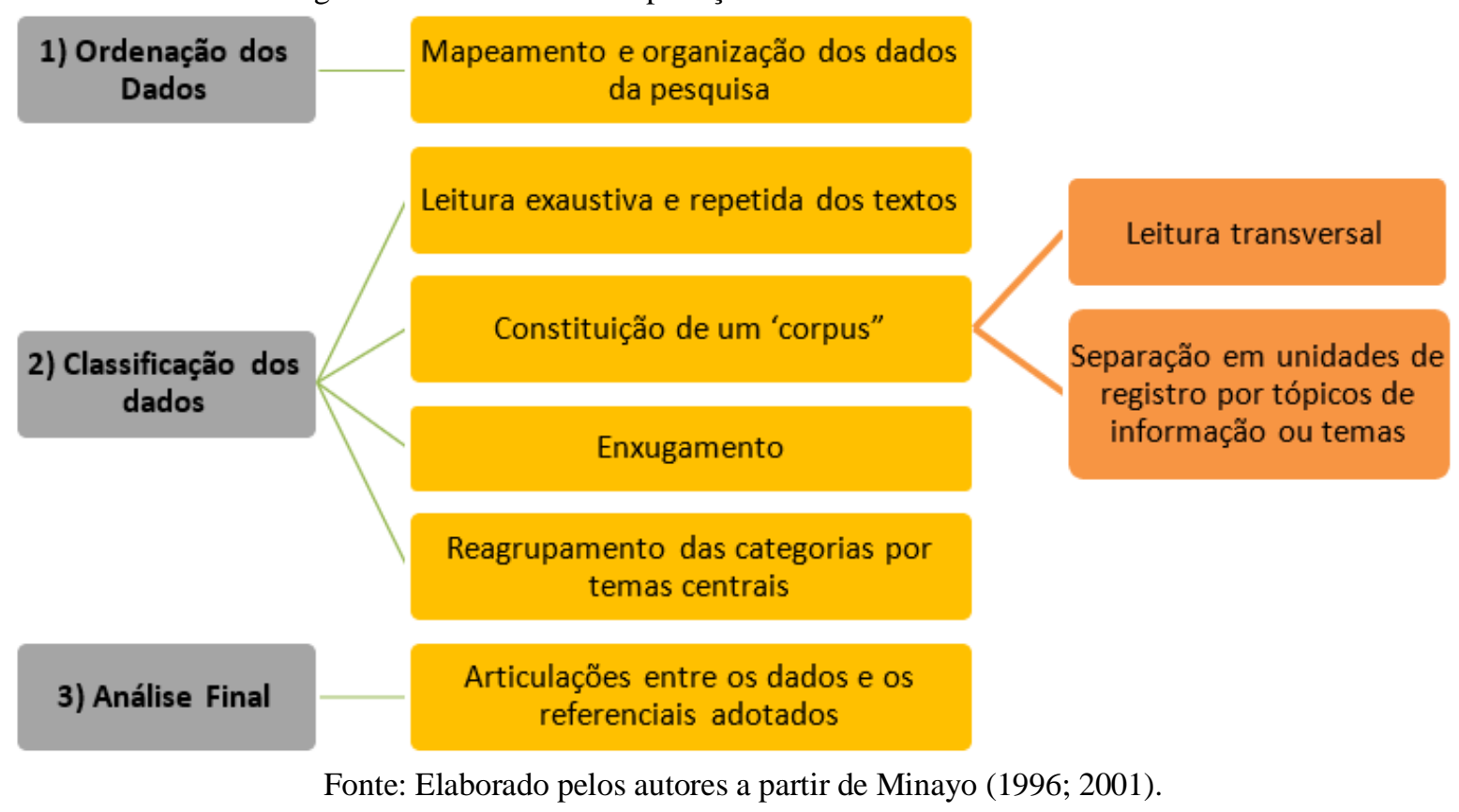

Os participantes da pesquisa são aqui entendidos e nominados como interlocutores, uma vez que, ao responderem as questões propostas, se colocam em diálogo com os autores que, por estarem implicados ao trabalho que constitui o pano de fundo deste estudo, retroalimentam as ações do próprio projeto a partir dos dados produzidos e da análise empreendida. Para fins de identificação, os excertos apresentados na íntegra estão identificados pelo código "INT", referente ao termo "interlocutor" e numerados sequencialmente, por exemplo "INT1", "INT2" e, assim, sucessivamente, até o "INT51". 
Neste contexto, a escuta sensível ${ }^{6}$ configura uma necessária postura do pesquisador e, aqui, como um princípio metodológico do estudo, apoiada no escutar/ver com empatia, sentindo o "universo afetivo, imaginário e cognitivo do outro para 'compreender do interior' as atitudes e os comportamentos, o sistema de ideias, valores e de símbolos" (MACEDO, 2012, p. 67-68).

\section{DisCUSSÃO DOS DADOS}

Para além do que se defendeu como postura metodológica, é importante destacar que a compreensão da realidade dada a partir dos dados produzidos está conduzida, tanto pelas dimensões temporal e espacial quanto pela dimensão de sentido, pois os interlocutores constroem interações com significados e significações concretas. Assim, passamos a apresentar o resultado deste processo de construção analítica em dois grandes campos temáticos, o primeiro reflete sobre as concepções dos professores iniciantes sobre formação continuada e o segundo campo ingressa diretamente nas contribuições que o Projeto Saberes em Diálogo possa aportar à inserção na carreira docente.

\subsection{CONCEPÇÕES DO PROFESSOR INICIANTE SOBRE FORMAÇÃO CONTINUADA}

Compreender as concepções dos interlocutores da pesquisa acerca da formação continuada constitui um movimento que busca, ao mesmo tempo, conhecer e vislumbrar possibilidades, num processo que se retroalimenta. As respostas dos professores indicam, por um lado, uma visão mais clássica do tema, que durante muitos anos representou a síntese do que a literatura neste campo colocava em discussão e, por outro os professores sinalizam para elementos outros, que estão alinhados ao que o trabalho proposto no âmbito da RMEC tem exercitado junto aos coletivos de professores e que assinalam para uma visão de formação como um processo contínuo, reconhecendo elementos como a colaboratividade e trocas entre pares.

Nas respostas obtidas sobre a compreensão do significado de formação continuada, 39\% indicaram a ideia de reciclagem, aperfeiçoamento, atualização e capacitação. Já $22 \%$ acreditam que a formação continuada se dá ao longo da carreira docente e de maneira permanente. $17 \%$ consideram que a formação ocorre via cursos, seminários, oficinas, pós-graduação e palestras. $11 \%$ destacam a formação em serviço e a trocas entre pares. $8 \%$ como continuidade da formação inicial e $3 \%$ acenam para a prática da pesquisa como estratégia formativa.

\footnotetext{
${ }^{6}$ O termo escuta-sensível é explorado por René Barbier (2002) e se apoia na empatia com a qual o pesquisador deve saber sentir o universo afetivo, imaginário e cognitivo do outro para poder compreender de dentro suas atitudes, comportamentos e sistema de ideias, de valores de símbolos e de mitos.
} 
Se, por um lado, as respostas dos professores sugerem em grande parte uma compreensão tradicional de formação continuada, com foco na atualização, aperfeiçoamento, reciclagem e capacitação, por outro, sinalizam para um entendimento da formação continuada como um processo permanente, que se desenvolve ao longo de todo o percurso profissional. Nesta segunda direção, reside a aposta do trabalho realizado no Projeto Saberes em Diálogo e destacam-se alguns excertos que podem ampliar a compreensão do que se faz enquanto formação continuada: “A formação continuada nos permite ampliar o nosso campo de atuação, nos permite ressignificar aspectos já existentes e permite estarmos sempre atualizados" (INT47). Pensar a formação continuada como um processo permanente, nos leva a considerar que "a experiência vivida é refletida como formação permanente e para a formação permanente é pauta central" (MACEDO, 2015, p. 41) e se transforma em um princípio formativo do trabalho, com o qual todas as ações e estratégias formativas que se possam pensar partam deste pressuposto. Assim: "Entendo por qualificação profissional suporte para que os professores possam compartilhar suas experiências e também buscar um novo entendimento, renovação e modificação de suas práticas" (INT19).

A compreensão da formação continuada como um continuum à formação inicial aparece também nas respostas, embora em menor percentual. O estudo desenvolvido por Ávalos (2016) aponta que os professores iniciantes não são simples praticantes inexperientes quando começam a ensinar, pois vêm com visões sobre o ensino, posições pessoais, que interagem com o ambiente de políticas e cultura de suas escolas, ou como diz um dos interlocutores "a formação continuada é um processo constante e permanente de aperfeiçoamento dos saberes do professor(a)" (INT16).

Parece se estar em uma dinâmica de tensão entre o que seria o clássico (também aqui visto como tradicional na formação e, portanto, reciclagem/capacitação) e na outra ponta tencionada a aposta nas trocas entre pares e na colaboratividade. Esse deslocamento, na verdade sob nosso ponto de vista, realoca o lugar do sujeito como produtor de conhecimento e não como mero receptor de um conhecimento produzido em terras distantes, conforme historicamente aprendemos a valorizar, um dos efeitos da trágica experiência da colonização, como bem indica Solano-Alpizar (2015) que, na busca por construir uma ciência com legitimidade e com estatuto de universalidade, acabou remetendo para "a negação de outras epistemes e outras práticas socioculturais, incluindo as suas próprias” (p.121). 
Os professores foram questionados sobre o que consideram que, após a formação inicial, tenha sido mais relevante na formação continuada. A figura 2 apresenta a síntese das respostas.

Figura 2 - Ao longo da vida profissional, após a formação inicial, o que você considera que tenha sido mais importante na/como formação continuada?

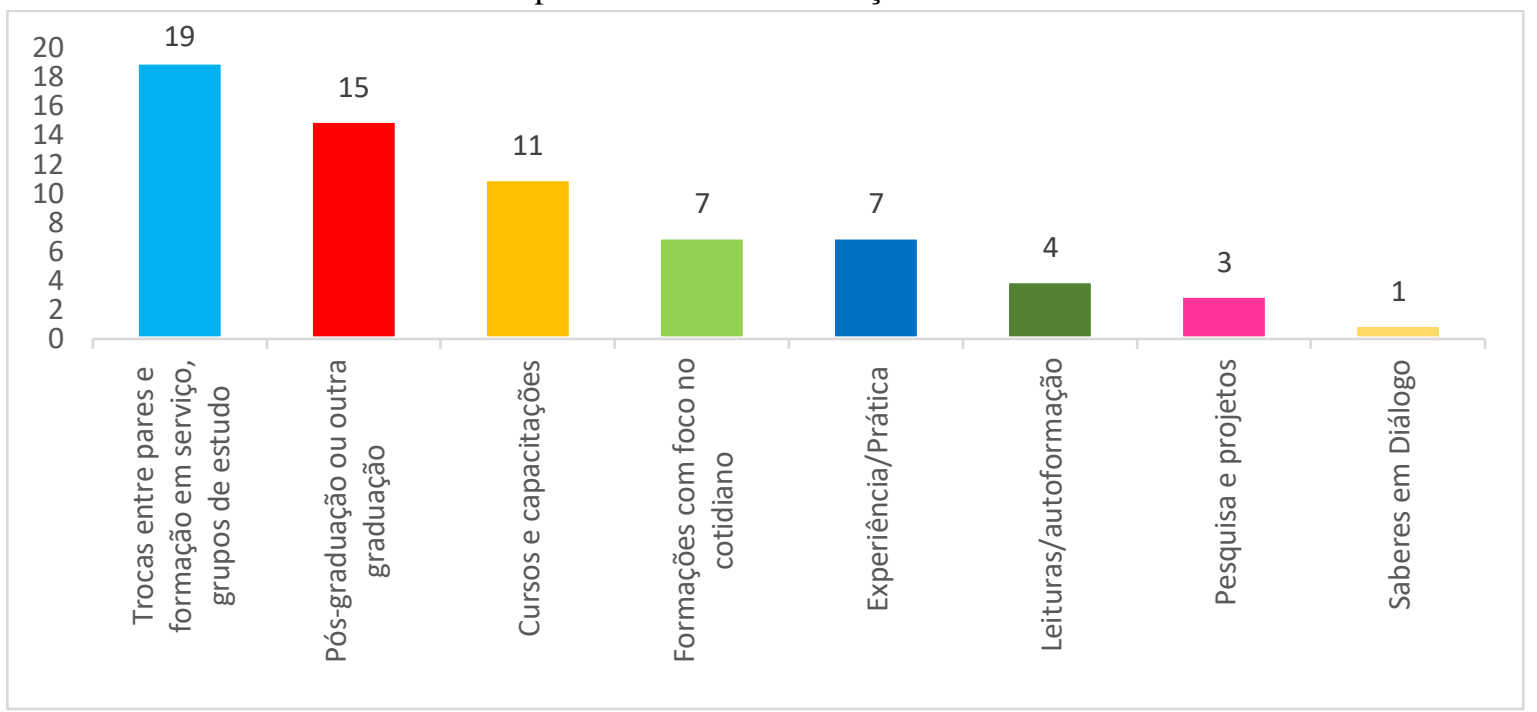

Fonte: Comissão Coordenadora do Projeto Saberes em Diálogo (2019).

Os elementos apontados nessa questão dialogam de modo muito próximo às concepções dos professores sobre formação continuada, permitindo-nos inferir que as experiências vividas vão moldando as compreensões que se tem acerca do trabalho que se faz, até mesmo em contraponto ao que a literatura tradicionalmente vem considerando como formação continuada de professores. Sobre o que tenha sido mais importante na formação continuada experienciada, alguns dos professores apontam que "as aulas, as vivências do grupo, as contribuições de cada um, como também cursos, oficinas, oportunidades de construções (artigos, trabalhos, pesquisas), só agrega e ganha uma grande importância" (INT47). A possibilidade de trocas, compartilhamentos e interação entre pares é um elemento que vem ganhando força nas discussões sobre formação de professores e recoloca o professor num lugar de protagonismo do seu trabalho, junto aos seus colegas, constituindo uma ruptura com a ideia convencionalmente difundida do especialista que vem "ensinar ao professor" aquilo que ele deve fazer. "O mais importante é quando você consegue relacionar a sua prática do dia a dia com a teoria e, quando esta teoria auxilia de alguma forma a refletir sobre o seu trabalho pedagógico" (INT19).

Ávalos (2009) ressalta que olhar para o trabalho dos colegas é uma das condições em que o trabalho docente é realizado e ocorre naturalmente entre os professores que interagem no mesmo espaço. "A troca de experiências pedagógicas com os colegas nos momentos de 
formação" (INT10), numa dinâmica que prima pelo compartilhamento e pelo caráter de coletividade, constitui uma das possibilidades de qualificação do trabalho docente desde onde se está e com as pessoas que lá estão (WALSH, 2009).

A "troca de experiências" a que se referem os professores não atua exatamente como uma troca, em que, ao entregar aquilo que tenho, recebo algo em troca. As experiências vividas ficam com o professor e aquilo que é oferecido ao colega, na condição de compartilhamento, na relação dialógica que se estabelece, se transforma em reflexões e aprendizagens outras, para ambos os envolvidos. Ou como nos fala um dos interlocutores: "a troca é sempre produtiva porque, ao mesmo tempo que apresentamos nossos trabalhos, também ouvimos dos colegas de outras escolas e percebemos que existe uma sintonia, mesmo que distante" (INT46) e "conhecer outras propostas que dão certo em outras escolas, debater sobre fundamentação teórica com outros olhares são (sic) uma experiência riquíssima!” (INT18).

A necessidade de relacionar prática à teoria e vice-versa, como referiu o INT18, embora já seja algo que há muito se busque no campo da educação, aqui toma um sentido outro: a contribuição das pesquisas realizadas no Projeto Saberes em Diálogo, por exemplo, para o cotidiano das escolas, tomando por referência os sujeitos que fazem parte do contexto, que estão "dentro" dele, garantem o fortalecimento de um protagonismo nas ações. De acordo com Ferraço (2007, p.91), “os sujeitos dos cotidianos das escolas nos têm ensinado que, nas redes cotidianas, o eu só se produz, só se constitui nas relações com o outro" e, por isso, formar-se professor a partir de seu próprio lugar se torna impregnado de sentido. O INT4 destaca, na mesma perspectiva, que é "a formação de um professor pesquisador, o fato da pesquisa fazer parte da minha constituição como professor, dessa forma contribuindo para a minha prática", confirmando o quanto o eu só se produz nas relações com o outro. Inevitavelmente ingressa nessa lógica uma outra questão que na dinâmica do trabalho do Projeto Saberes em Diálogo se torna evidente. Tem sido necessário construir junto aos educadores, tanto iniciantes na profissão quanto educadores com maior tempo na profissão, a legitimidade e o estatuto de "cientificidade" do processo, ou seja, o que se produz nas reflexões constituem-se elementos epistêmicos de um conhecimento que se aprimora a partir de espaços de compartilhamento e reflexão. É um aprender a desaprender para aprender de novo sob outras bases, agora não mais tão distantes, mas pelo contrário, respondendo ao que mobiliza a curiosidade no cotidiano da ação docente e "cuestionar esta visión y desaprenderla constituye um reto ineludible para un verdadeiro processo de descolonización educativa" (SOLANO-ALPIZAR, 2015, p. 121). 


\subsection{CONTRIBUIÇÕES DE UM PROGRAMA DE FORMAÇÃO À INSERÇÃO DO PROFESSOR NA} PROFISSÃO

Ávalos (2016) aponta que a necessidade de orientação e de apoio aos professores iniciantes tem sido amplamente reconhecida, ainda que não haja programas específicos de indução em grande parte dos países que compuseram o estudo por ela realizado. O suporte ao professor iniciante geralmente se dá através de assistência espontânea, oferecida pelos colegas, independente dos sistemas formais de indução. A RMEC não possui um programa de indução de professores iniciantes, entretanto, a experiência vivenciada no âmbito do Saberes em Diálogo tem nos permitido refletir acerca da potencialidade das ações deste projeto na inserção destes docentes. Como apontam Silva e Machado (2020), tem-se pensado o processo de formação continuada como a possibilidade de um "movimento que se desloca epistemicamente para assumir o lugar de produção do conhecimento, o lugar do chão da escola, que historicamente foi relegado ao lugar de ação e de práticas de ensino" (p. 7). Aqui a noção de "chão de escola" ganha duas dimensões, em que vale a pena o destaque. Na primeira delas reportamos ao lugar físico, propriamente falando, o lugar onde acontecem as experiências com os agentes que aí atuam e circulam neste espaço, constituindo-se como participantes de um processo de construção de saberes. Assim, o chão da escola é o espaço das vivências, dos encontros e das aprendizagens. Na outra dimensão, o chão da escola ganha status de categoria epistemológica, que reivindica o lugar de produção de conhecimentos, lugar (geo)epistêmico desde onde se produz conhecimentos outros e também desde o com quem aí se encontra.

Ainda que possa haver diferentes motivações e trajetórias para se tornar professor, ao adentrar na profissão, identificam-se convergências nos desafios, requerendo um envolvimento e compartilhamento de tarefas e responsabilidades semelhantes (ÁVALOS, 2016). Perguntouse aos professores qual a principal motivação para participar do Saberes em Diálogo; as respostas concentraram-se majoritariamente em "melhorar a prática docente" com $51 \%$. "Busca de parcerias para discutir temas de meu interesse na educação" foi a indicação de $24 \%$ dos educadores. "Interesse em ingressar em cursos de pós-graduação (mestrado ou doutorado)" foi indicado por $21 \%$ dos professores respondentes. Em torno de $4 \%$ apontam para a divulgação de seu trabalho, interação na rede e validação de suas práticas como o motivo pelo qual buscam a participação no projeto Saberes em Diálogo.

A qualificação das práticas pedagógicas a partir do desenvolvimento de pesquisas focadas nos contextos de trabalho já está consolidada como objetivo principal do Projeto, 
contudo, tanto a busca por parcerias quanto o interesse em cursar um curso de pós-graduação, potencializado pela participação dos professores nas estratégias do projeto, foram se constituindo como elementos motivacionais no percurso do trabalho. Um dos interlocutores aponta esta questão: "Para os professores que desejam ingressar em um programa de pósgraduação é muito interessante a participação nos Saberes, é uma forma de começar um problema de pesquisa" (INT16). De igual modo acena: "para aqueles que não desejam a pósgraduação, a participação no Saberes pode trazer novos conhecimentos e o mais importante: compartilhamento das suas experiências com os colegas da Rede” (INT16). A escuta atenta é uma das características que emergem dos registros "ouvir os colegas de outras escolas contando sobre as suas práticas é muito bom, nos faz pensar na identidade docente do município" (INT 19) ou "somos professores de escolas diferentes, vivências e idades diferentes, mas com experiências profissionais cotidianas tão semelhantes". (INT19)

Machado, Silva e Silva (2019) afirmam que um dos momentos coletivos do trabalho durante o ano é a realização do Seminário Municipal, onde se apresentam as pesquisas produzidas nos Grupos de Estudos. Nesse sentido, acaba por "evidenciar uma clara perspectiva de trabalho democrático, em que os sujeitos são chamados a participar, a compartilhar, a se colocar como protagonista e como intelectual do seu fazer pedagógico" (p. 473-474).

Quando questionados se a participação no Projeto Saberes em Diálogo contribui para sua atividade docente, $94 \%$ dos interlocutores considerou que sim. Um dos interlocutores assim expressa: "amplia o nosso horizonte, sendo pela pesquisa, pelas trocas com o grupo, pelas inquietudes as quais desencadearam o nosso projeto" (INT47). As dinâmicas do trabalho coletivo acabam por contribuir para reforçar o lugar do educador no processo auto formativo, ideia esta em consonância com o que vem evidenciado na literatura nacional e internacional na área de formação continuada, entretanto, sem tantos avanços como se desejaria. Outro educador enfatiza, assim, os sentidos que a experiência vivida foi agregando à prática cotidiana da docência: “O professor tem um compromisso com a sua autoformação e essa não pode vir de fora, precisa inicialmente partir do sujeito olhando sobre a sua prática. Estou olhando com maior cuidado, criando novos critérios de escolhas para preparar a minha aula" (INT 19). Ou, então, quando diz: "Escrever sobre a prática dos outros parecia fácil, na especialização e doutorado, o difícil é você escrever sobre a sua própria prática, ser o pesquisador e sujeito da pesquisa. [...] é impossível sair dessa experiência da mesma forma que se entra" (INT19). 
Do chamado isolamento ou solidão pedagógica, umas das características da profissão docente, o sentimento de estar pertencendo a um grupo, a um projeto, desloca o professor iniciante e o insere em um grande coletivo, em que o objetivo pela qualidade daquilo que se pratica na profissão é o grande mobilizador pela participação ativa no processo formativo desencadeado no Projeto Saberes em Diálogo, “A parceria, colaboração e estudo com o grupo de professores qualificou muito!” (INT34).

Aliado a isso, outro aspecto entra em cena: a oportunidade de elevação da autoestima profissional, uma vez que, como diz este interlocutor, "o Saberes nos mostra o quanto somos capazes de mostrar nosso trabalho e como ele é importante na formação dos nossos alunos" (INT18). Tais excertos, destacam em grande parte a possibilidade do professor em colocar-se em movimento, em desacomodar-se, em buscar na experiência de olhar para sua prática de forma curiosa, reflexiva, crítica e propositiva, contribuindo, inclusive para o bem estar do professor, para além da autoestima, conforme refere um dos participantes: "esta é minha terceira participação no Saberes e me sinto encorajada e valorizada com o projeto nos seminários, nas reuniões e muito nos grupos de estudos!" (INT34).

Em estudo recente, Silva e Machado $(2020)^{7}$ exploraram e sistematizaram os princípios que vieram à tona do conjunto de estratégias experimentadas no Projeto Saberes em Diálogo. Tal movimento aposta em um trabalho que não está definido a priori, mas que valoriza o processo de construção a muitas mãos. Entre os anos de 2017 e 2019, destacaram-se oito princípios, que foram apresentados aos professores participantes, questionando sobre a sua relevância. As respostas foram sintetizadas na Figura 3.

\footnotetext{
${ }^{7}$ Encontram-se diferenças de redação na apresentação dos oito princípios entre o questionário usado como referência para este estudo e a publicação (SILVA E MACHADO, 2020). Tais diferenças se devem ao fato de a elaboração da redação de forma refletida e aprofundada se dá a partir da realização desta produção, cabe lembrar que estamos lidando com um projeto formativo em pleno processo de execução e sendo acompanhado por um processo permanente de sistematização, reflexão e de reorientação.
} 
Figura 3 - Princípios que pautam o Projeto Saberes em Diálogo que considera mais relevantes

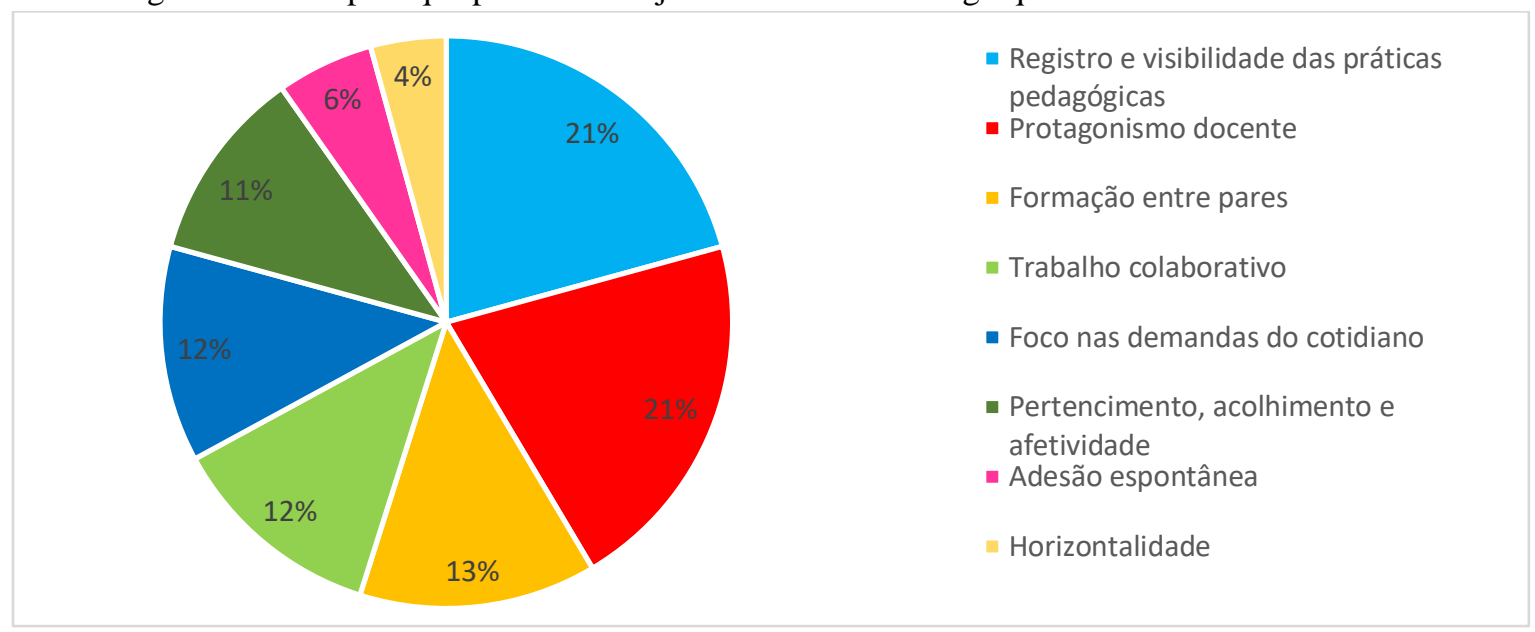

Fonte: Comissão Coordenadora do Projeto Saberes em Diálogo (2019).

Observa-se certa harmonia estatística entre os percentuais obtidos entre os princípios que orientam o trabalho no Projeto Saberes em Diálogo. O registro e visibilidade das práticas docentes se coloca como uma das possibilidades de compartilhamento do conhecimento pedagógico construído cotidianamente, na perspectiva do professor como intelectual do seu trabalho. A falta de registro e sistematização inviabiliza que as experiências vivenciadas sejam compartilhadas e possam chegar a outros docentes, num movimento que, por outro lado, atua na valorização daquilo que é próprio do cotidiano, como algo que tem valor e é reconhecido pelos pares (SILVA e MACHADO, 2020). Ou, como na fala de um dos interlocutores, ao referir que "torna visível o trabalho realizado, oportuniza a reflexão, além de ser um importante espaço de discussão, pertencimento e acolhimento do trabalho docente como um trabalho intelectual" (INT24). Ferraço e Silva (2018) apontam que o ato de se permitir escrever, potencializa os processos formativos e a produção dos "saberes-fazeres" (p. 1), sendo esta entendida como uma possibilidade que, por um lado, sistematiza conhecimentos pedagógicos e, por outro, socializa aquilo que foi produzido, conduzindo o vivido individualmente a um lugar de reflexão coletiva.

Os princípios do protagonismo docente, da formação entre pares e do trabalho colaborativo não podem ser pensados de forma dissociada, pois um pressupõe a articulação dos demais para que se efetive. Um dos interlocutores sintetiza, referindo-se à sua participação no projeto: "tanto no que se refere a reflexão a que me proponho enquanto docente como pela possibilidade de dialogar com minhas colegas, conhecendo melhor a rede, seus anseios, necessidades e potencialidades" (INT44).

Embora o foco do Saberes em Diálogo esteja centrado na formação dos professores, a qualificação da aprendizagem dos alunos constitui uma finalidade última dos processos 
formativos e está intrínseca a qualquer ação que se pretenda no campo da educação. Um dos participantes externou esta relação, ao referir que "através do Saberes em Diálogo, pude perceber o quão rico e produtivo os projetos desenvolvidos em sala de aula ou na escola, podem vir a ser" (INT38). A mesma educadora, se referindo às crianças, assim continua: "elas construíram hipóteses, formularam questionamentos e se envolveram de fato com o trabalho, tentando adquirir seu conhecimento que talvez não seja mais empírico e sim sustentado em uma base mais solidificada e estruturada" (INT38). É este espaço de reflexão sobre a prática docente que o projeto de formação continuada acabou por constituir e construir junto aos educadores. Não é algo que emerge como uma política pública voltada para atender aos educadores, mas uma ação que parte da escuta dos educadores, tomando o chão da escola como ponto de referência para orientar as ações que vão ser mobilizadoras das reflexões e das dinâmicas que materializam a formação na rede, com a rede e em rede.

Por outro lado, um dos grandes desafios que tem se feito presente, de forma insistente no trabalho, diz respeito à falta de tempo para a formação. "É sempre positiva a troca de experiências entre nossos pares, se posso colocar algo para ser melhorado são as questões de horário para melhorar a possibilidade de participação" (INT 33). Tal questão tem sido destacada de forma recorrente pelos participantes e tem preocupado a equipe gestora do projeto:

Tudo muito organizado, só os horários de encontros no início da noite é que é complicado, principalmente para quem trabalha o dia todo, deveriam ser feitas em horário de trabalho, com participação mediante convocação, após o horário de trabalho é muito complicado, é algo que avaliarei para participar no próximo ano (INT12).

Essas questões do cotidiano da escola, como a liberação de professores caso os encontros sejam em horário de trabalho, são adversidades que buscam ser solucionadas/pensadas para o seguimento do projeto. A formação dos docentes dentro do horário em que estão trabalhando é uma alternativa para auxiliar na dedicação de cada professor a sua pesquisa. E aqui vem residindo uma das fraturas no campo de se pensar políticas públicas para a formação continuada, mas isso já exige outro espaço.

\section{CONSIDERAÇÕES}

Com base no que foi exposto neste trabalho, podemos pontuar alguns aspectos que permitem evidenciar o quanto a formação continuada de professores, em especial, a que contempla a particularidade da inserção de novos profissionais na área da docência se apresenta como um campo ainda a ser desbravado a partir da perspectiva da produção acadêmica e como 
processo de investimento desde as ações que se voltam a formular políticas formativas nas diferentes esferas públicas.

Um dos primeiros aspectos que destacamos refere-se ao fato de que a consonância com que a literatura internacional aponta como exigência se traduz para o contexto nacional brasileiro, ou seja, somos pródigos em seguir os passos do que países desenvolvidos produzem como orientações para suas realidades, mas sem o cuidado de considerar as particularidades próprias de nossos contextos.

O Projeto Saberes em Diálogo parece responder positivamente aos desafios apontados pelos educadores no que diz respeito aos desafios da inserção docente na profissão e na rede. A criação de um espaço privilegiado de trocas, pautado em um dos princípios que orientam o trabalho no projeto, acaba por dar sustentação a vários desafios que emergem das ações docentes cotidianas de quem está iniciando na profissão. Assim, a questão levantada no início deste trabalho pode receber uma resposta de caráter mais positivo do que negativo. Olhar para esses professores, que chegam à docência, e auxiliar no sentimento de pertencimento deles a um espaço, uma coletividade, cultiva um trabalho que valoriza a profissão e o alcance de seu papel no mundo, assim, o privilégio de pesquisar sua própria prática, o chão de escola, é poder pertencer e modificar seu cotidiano. E isso, para um professor que recentemente se insere na profissão docente, veio se traduzindo como um ganho para reduzir a tensão e a insegurança.

Os dados que aportam este estudo nos possibilitam articular desde o que indica a literatura, contribuindo com elementos que emergem da experiência vivida junto a este coletivo de professores, ao mesmo tempo que retroalimentam a experiência em andamento, tanto formativa quanto dos educadores iniciantes na profissão. Ao mesmo tempo, nos coloca em alerta permanente, como pesquisadores, num movimento que privilegia a escuta sensível como postura e que, com isso, possibilita que as discussões travadas estejam articuladas com os contextos em que se dá a construção dos saberes-fazeres dos professores, ou seja, desde onde se está (o chão da escola) e com quem se está (os professores) sem perder de vista o para além de onde se está (experiências outras).

\section{REFERÊNCIAS}

ANDRÉ, Marli Eliza Dalmazo Afonso de. Professores iniciantes: egressos de programas de iniciação à docência. Revista Brasileira de Educação, v. 23, 2018. p. 1-20. Disponível em: http://dx.doi.org/10.1590/S1413-24782018230095 Acesso em: 01 de mar. de 2021.

ARIAS, Patricio Guerrero. Corazonar: uma antropologia comprometida com la vida. Quito, Ecuador; Abya Yala, 2010. 
ÁVALOS, Beatrice. La inserción profesional de los docentes. Profesorado. Revista de Currículum y Formación de Profesorado, vol. 13, núm. 1, abril, 2009. pp. 43-59. Universidad de Granada - Granada, España. Disponível em: https://www.redalyc.org/articulo.oa?id=56711733004 Acesso em: 04 de mar. de 2021.

ÁVALOS, Beatrice. Learning from Research on Beginning Teachers. In: LOUGHRAN, John; HAMILTON, Mary Lynn (Ed.). International Handbook of Teacher Education.

Singapore: Springer, 2016. p. 487-552.

BARBIER, René. A pesquisa-ação. Brasília: Plano Editora, 2002.

CONGEPRINCI. Congresso Internacional Sobre Professorado Principiante e Inserção Profissional à Docência - 4 CONGEPRINCI. Anais. Curitiba: UTFPR, 2014.

FALS BORDA, Orlando. Una sociología sentipensante para América Latina. México, D. F.: Siglo XXI Editores; Buenos Aires: CLACSO, 2015.

FERRAÇO, Carlos Eduardo. Pesquisa com o cotidiano. Educação \& Sociedade, v.28, n.98, jan/abr 2007. p.73-95. Disponível em: https://www.scielo.br/pdf/es/v28n98/a05v2898.pdf Acesso em: 16 de mar. de 2021.

FERRAÇO, Carlos Eduardo; SILVA, Tamili Mardegan da Silva. A escrita como experiência cotidiana: pistas para pensar a formação de professores. Revista de Educação, Ciência e Cultura, v. 23, n. 2, 2018. p. 171-186. Disponível em:

https://revistas.unilasalle.edu.br/index.php/Educacao/article/view/4551 Acesso em: 16 de abr. de 2021.

GABARDO, Claudia Valéria; HOBOLD, Márcia de Souza. Professores iniciantes: acolhimento e condições de trabalho. Atos de Pesquisa em Educação. v. 8, n. 2, mai./ago. 2013. p.530-549. Disponível em: http://dx.doi.org/10.7867/1809-0354.2013v8n2p530-549 Acesso em: 10 de mar. de 2021.

GARCIA, Carlos Marcelo. O professor iniciante, a prática pedagógica e o sentido da experiência. Formação Docente, Belo Horizonte, v. 02, n. 03, p. 11-49, ago./dez. 2010. Disponível em: http://formacaodocente.autenticaeditora.com.br Acesso em: 16 de abr. de 2021.

GARCIA, Carlos Marcelo; VAILLANT, Denise. Políticas y programas de inducción en la docencia en Latinoamérica. Cadernos de Pesquisa, v. 47, n. 166, 2017. p. 1224-1249. Disponível em: https://dialnet.unirioja.es/servlet/articulo?codigo=6211668 Acesso em: 16 de abr. de 2021.

GATTI, Bernadete Angelina. Formação de professores, complexidade e trabalho docente. Revista Diálogo Educacional, Curitiba, v. 17, n. 53, 2017. p. 721-737. Disponível em: https://periodicos.pucpr.br/index.php/dialogoeducacional/article/viewFile/8429/17739 Acesso em: 13 de mar. de 2021.

GATTI, Bernadete Angelina; BARRETO, Elba Siqueira de Sá; ANDRÉ, Marli Eliza Dalmazo Afonso de; ALMEIDA, Patrícia Cristina Albieri de. Professores do Brasil: Novos 
cenários de formação. Brasília: UNESCO, 2019. Disponível em:

https://unesdoc.unesco.org/ark:/48223/pf0000367919 Acesso em: 12 de abr. de 2021.

GATTI, Bernadete Angelina. Perspectivas da formação de professores para o magistério na educação básica: a relação teoria e prática e o lugar das práticas. Revista da FAEEBA Educação e Contemporaneidade, v. 29, n. 57, 3 abr. 2020. p. 15-28. Disponível em: https://revistas.uneb.br/index.php/faeeba/article/view/8265/5327 Acesso em: 12 de abr. de 2021.

GONÇALVES, Gláucia Signorelli de Queiroz. Inserção profissional de egressos do PIBID: desafios e aprendizagens no início da docência. 2016. 243f. Tese (Doutorado em Educação) — Pontifícia Universidade Católica de São Paulo, São Paulo, 2016.

ISAIA, Silvia Maria de Aguiar; BOLZAN, Doris Pires Vargas. Compreendendo os movimentos construtivos da docência superior: construções sobre pedagogia universitária. Linhas críticas, v. 14, n. 26, 2008. p. 25-42. Disponível em: http://periodicos.unb.br/index.php/linhascriticas/article/view/3424 Acesso em: 12 de abr. de 2021.

MACEDO, Roberto Sidnei. Outras luzes: Um rigor intercrítico para uma etnopesquisa política. In: MACEDO, Roberto Sidnei; GALEFFI, Dante; PIMENTEL, Álamo. Um rigor outro sobre a qualidade na pesquisa qualitativa: educação e ciências humanas.

EDUFBA, 2009. Disponível em: http://books.scielo.org/id/s6/pdf/macedo9788523209278.pdf Acesso em: 12 de abr. de 2021.

MACEDO, Roberto Sidnei. A Etnopesquisa implicada: Pertencimento, criação de saberes e afirmação. Brasília: Liber Livro Editora, 2012.

MACEDO, Roberto Sidnei. Pesquisar a experiência compreender/mediar saberes experienciais. $1^{\mathrm{a}}$ edição, Curitiba, PR. CRV, 2015.

MACHADO, Juliana Aquino; LEDUR, Rejane Reckziegel; SILVA, Gilberto Ferreira da. (Orgs.) Saberes em diálogo. Educação básica, universidade e pesquisa. Canoas, Editora Unilasalle, 2018. Disponível em: http://www.canoas.rs.gov.br/wpcontent/uploads/2018/07/AF-Saberes-em-dialogos.pdf Acesso em: 12 de abr. de 2021.

MACHADO, Juliana Aquino; SILVA, Juliana Cristina da; SILVA, Gilberto Ferreira da. Dos tempos coletivos: horizontes na formação de professores em rede. In: MACHADO, Juliana Aquino; LEDUR, Rejane Reckziegel; SILVA, Gilberto Ferreira da; SILVA, Juliana Cristina da (orgs.) Saberes em diálogo: docência, pesquisa e práticas pedagógicas: volume 2. Canoas, RS: Secretaria Municipal da Educação: Ed. Unilasalle, 2019. Disponível em: https://www.canoas.rs.gov.br/wp-content/uploads/2019/11/Ebook-Saberes-emDialogo-Vol-22018.pdf Acesso em: 12 de abr. de 2021.

MINAYO, Maria Cecília de Souza. O desafio do conhecimento: pesquisa qualitativa em saúde. São Paulo-Rio de Janeiro, HUCITEC-ABRASCO, 1996.

MINAYO, Maria Cecília de Souza (Org.) Pesquisa social: teoria, método e criatividade. Petrópolis, RJ: Vozes, 2001. 
SILVA, Gilberto Ferreira da; MACHADO, Juliana Aquino. Saberes em diálogo: a construção de um programa de formação docente em uma rede municipal de ensino. Revista Iberoamericana de Educación / Revista Ibero-americana de Educação. Vol. 77, núm. 2, 2018. p. 95-114. Disponível em: https://rieoei.org/RIE/article/view/3161/3978 Acesso em: 12 de abr. de 2021.

SILVA, Gilberto Ferreira da; MACHADO, Juliana Aquino. "Saberes em Diálogo”, um programa de formação continuada em rede: Universidade e Educação Básica. Arquivos Analíticos de Políticas Educativas, 28(68), 2020. p. 1-21 Disponível em: http://epaa.asu.edu/ojs/article/view/4937 Acesso em: 12 de abr. de 2021.

SOLANO-ALPIZAR, Jose. Descolonizar la educación o el desafío de recorrer un camino diferente. Revista Electrónica Educare. Vol. 19, nº1, enero-abril, 2015. p. 117-129. Disponível em: https://dialnet.unirioja.es/descarga/articulo/4895717.pdf Acesso em: 12 de abr. de 2021.

VAILLANT, Denise. Trabajo colaborativo y nuevos escenarios para el desarrollo profesional docente. Docencia, 60. Santiago, Chile, 2016. p. 5-13 Disponível em:

https://ie.ort.edu.uy/innovaportal/file/48902/1/trabajo-colaborativo-y-nuevos-escenariosdenise-vaillant.pdf Acesso em: 12 de abr. de 2021.

VAILLANT, Denise; GARCIA, Carlos Marcelo. EI ABC y D de la formación docente. Vol. 134. Narcea Ediciones, 2015.

WALSH, Catherine. Geopolíticas del conocimiento, interculturalidad y descolonización. Boletín ICCI-ARY Rimay, n. 60, marzo, 2004. pp. 1-6. Disponível em: http://icci.nativeweb.org/boletin/60/walsh.htm Acesso em: 12 de abr. de 2021.

WALSH, Catherine. "¿Son posibles unas ciencias sociales/culturales otras? Reflexiones en torno a las epistemologías decoloniales". Nómadas, n. 26, 2007. p. 102-113. Disponível em: http://nomadas.ucentral.edu.co/nomadas/pdf/nomadas_26/26_10W_Sonposiblesunascienciass ociales.pdf. Acesso em: 12 de abr. de 2021.

WALSH, Catherine. Interculturalidad crítica y pedagogía de-colonial: apuestas (des) de el insurgir, re-existir y re-vivir. UMSA Revista (entre palabras), v. 3, 2009. p. 1-29 Disponível em: https://redinterculturalidad.wordpress.com/2014/02/06/interculturalidad-criticaypedagogia-decolonial-catherine-walsh. Acesso em: 12 de abr. de 2021. 